\title{
15-year-old atrial pacing lead displaced into pulmonary artery - the consequences of prolonged observation.
}

\author{
Aneta Maria Polewczyk $k^{1, A-D, F}$, Maciej Polewczyk $2, A-D, F$, Andrzej Kutarskiª-A-F \\ A - Research concept and design, B - Collection and/or assembly of data, C - Data analysis and interpretation, \\ D - Writing the article, E - Critical revision of the article, F - Final approval of article
}

1 1st Department of Pediatrics, District Hospital Kielce, Poland

2 Acute Cardiac Care Unit, District Hospital, Kielce, Poland

3 Department of Cardiology, Medical University of Lublin, Poland

Address for correspondence:

Andrzej Kutarski, Department of Cardiology, Medical University of Lublin, Poland

email: a_kutarski@yahoo.com

Maciej Polewczyk, Acute Cardiac Care Unit, Swietokrzyskie Cardiology Center, Kielce, Poland

email: maciek.polewczyk@gmail.com

Aneta Maria Polewczyk, 1st Department of Pediatrics, District Hospital Kielce, Poland

email: an.tuchalska@gmail.com

\section{Introduction}

In the last twenty years, the number of cardiac implantable electronic device (CIED) implantations has markedly increased; proportionally the incidence of complications such as lead-related infective endocarditis (LRIE) and venous obstruction has grown too ${ }^{[1,2]}$. LRIE is a serious disease with an unpredictable course. Current guidelines (HRS 2009) recommend transvenous lead extraction (TLE) associated with long-term antibiotic therapy in each case (class IB). This procedure, when performed by an experienced operator, is safe and efficient ${ }^{[3]}$. However, approximately $10 \%$ of TLE procedures necessitate the use of additional tools used by interventional radiologists ${ }^{[1]}$. It may affect patients with occlusion of major thoracic veins, which was observed in 15-30\% of patients with a cardiac pacemaker. Significant stenosis is usually symptomless, because of bypass circulation, but it can be a cause of serious technical problems during extraction or addition of a new lead ${ }^{[4]}$.

The present case combines the mentioned issues in electrotherapy and TLE.

\section{Key words:}

transvenous lead extraction, lead-related infective endocarditis, lead displaced into pulmonary artery

\section{Case report}

We report a case of a 79-year-old man with a DDD pacemaker implanted in 1996 due to complete AV block, followed by revision surgery of the cardiac device due to pocket infection (PI) with simultaneous additional atrial and ventricular lead implantation in 2001 and further unit replacement in 2009. In October 2011 he was admitted to hospital with recurrent incidents of fever and pulmonary infections for the preceding six months. Laboratory tests revealed leukocytosis and elevated levels of inflammatory markers. Blood cultures were negative. Performed echocardiography enabled detection of vegetations on the leads in the right atrium (RA) and third-degree tricuspid regurgitation (Figure 1). After LRIE diagnosis the patient was transferred to the Reference Center

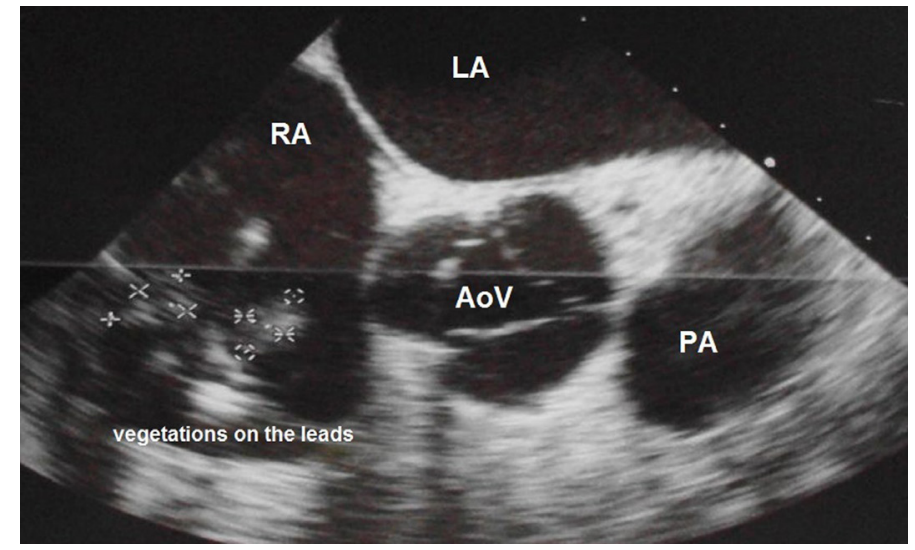


for Management of Lead Related Complications (Reference TLE Center) and qualified for an urgent TLE procedure. A fluoroscopic examination confirmed the displacement of the proximal ending of an old atrial lead into the pulmonary artery. Moreover, the lead formed a loop in the right atrium. Venography showed the occlusion of subclavian, brachiocephalic and superior cava veins (Figure 2). Initially, because

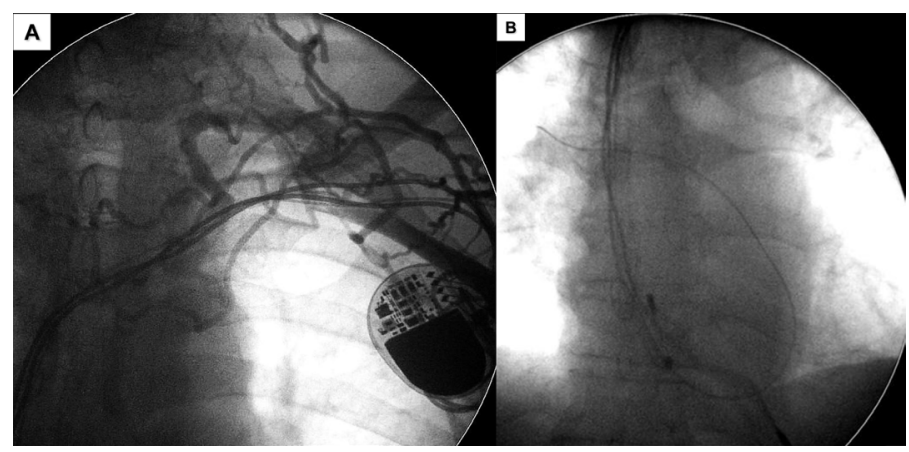

of pacemaker dependency, the patient required temporary pacing, which was provided conventionally, via the femoral venous approach. Subsequently, the operator removed the functional atrial and the non-functional old ventricular lead via the left subclavian approach using Byrd dilator mechanical sheaths (Cook, USA). The real challenge was the extraction of the non-functional atrial lead with the proximal ending absent in the pacemaker pocket. Using the pigtail catheter the lead was successfully reeled over the catheter and shifted to the superior cava vein and then grasped with a lasso. The next step involved removal of the lead with the Byrd dilator sheath (introduced over the lasso sheath) cutting the fibrotic tissue around the lead (Figure 3). The remaining functional ventricular lead was

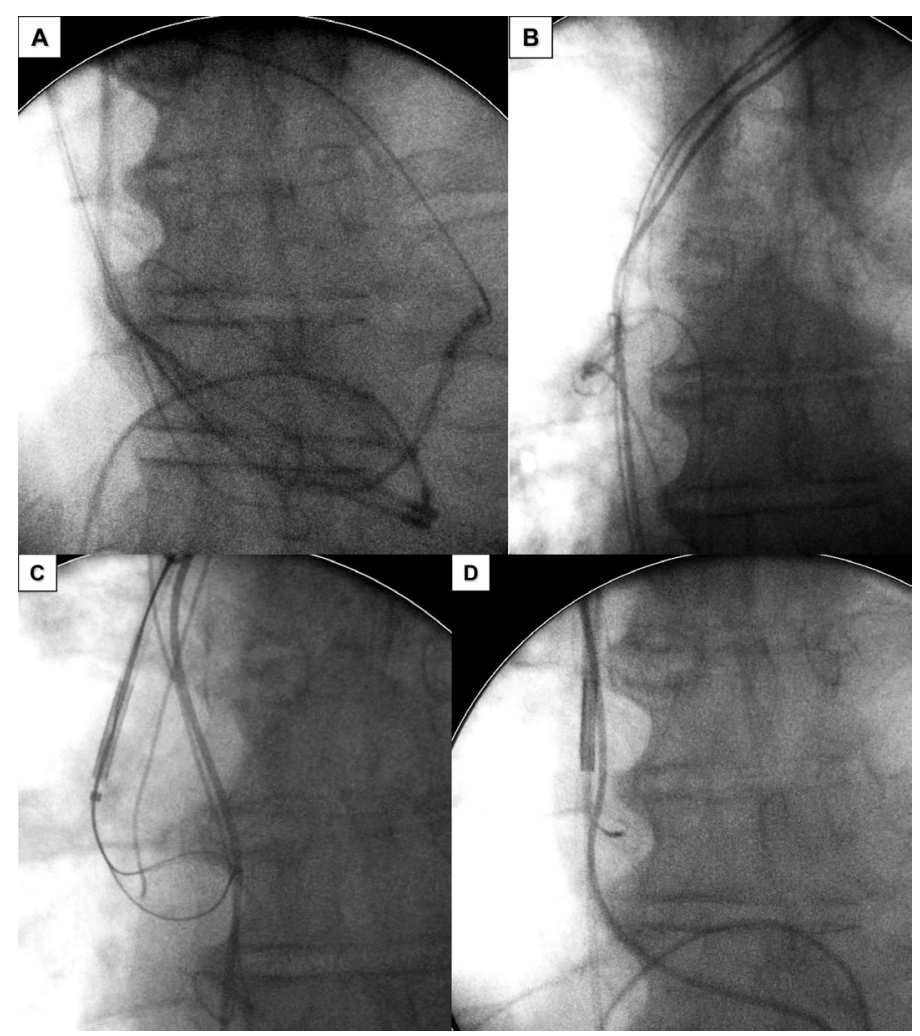

extracted without any difficulty. Prolonged temporary pacing with a soft screw-in lead was introduced via the left restored subclavian approach, and reimplantation of a new device was postponed. Even though the TLE procedure was complex and long, complete clinical and procedural success was achieved.

\section{Discussion}

This case illustrates difficulties during extraction of old, migrating pacing leads.

The number of pacing leads and a prior local infection of the pacemaker pocket have a significant impact on the development of systemic infection or vein occlusion. It is believed that obliteration in the vessels could be a reaction of an organism against purulence dispersion to the endocardium ${ }^{[5]}$. According to the current guidelines, LRIE has been diagnosed despite the lack of positive blood culture, which may be related to prior antibiotic therapy ${ }^{[3]}$. Infectious indications are important perioperative mortality factors, whilst long lead dwelling time (15 years in this case) is a risk factor for major complications of TLE ${ }^{[6,7]}$. The major impediment to a TLE procedure is the occlusion in the major thoracic veins, at the juncture of the brachiocephalic and superior cava vein in particular. It often requires extra tools, such as a pigtail or lasso catheter, not to mention an operator with great experience of lead extraction ${ }^{[8]}$. If the operation had been performed earlier, in 2001, when PI was diagnosed, it would have significantly reduced the technical difficulties. At that time, according to previous guidelines, the indications for TLE should have been considered as class IIa ${ }^{[9]}$; at present they are class ${ }^{[3]}$.

In our opinion, a lead displaced into the pulmonary artery is a serious threat to the patient's condition (it might lead to LRIE development, or pulmonary artery injury) and according to current guidelines, it could be regarded as a class IIa indication for TLE ${ }^{[3]}$. There are reports showing that removal of migrating leads usually requires a complex procedure; however, the efficacy is comparable to a routine extraction ${ }^{[10,11]}$. Nevertheless, it is still necessary to comply with the fundamental principles, which are immensely important for the life and health of the patients. In practice, it means avoiding abandonment of the leads, discontinuation of infected pockets' surgical revisions, and removal of free floating leads.

\section{References}

1. Tarakji KG, Wilkoff BL. Cardiac implantable electronic device infections: facts, current practice, and the unanswered questions. Curr Infect Dis Rep. 2014; 16:425.

2. Lelakowski J. Powikłania stałej stymulacji serca - problem o rosnącym znaczeniu. Folia Cardiologica Excerpta 2009, tom 4, nr 2, 69-72. (In Polish)

3. Wilkoff BL, Love CJ, Byrd CL et al. Transvenous lead extraction: heart rhythm society expert consensus on facilities, training, indications, and patient management. Heart Rhythm, 2009; 6: 1085-1104

4. Kutarski A, Pietura R, Młynarczyk K, et al. Pacemaker lead extraction and recapture of venous access: Technical problems arising from extensive venous obstruction. Cardiol J. 2012; 19(5):513-7 
5. Małecka B, Kutarski A, Zabek A, et al. Percutaneous removal of endocardial implantable cardioverter-defibrillator lead displaced to the right pulmonary artery. Cardiol J. 2010; 17(3):293-8.

6. Brunner MP, Cronin EM, Duarte VE, et al. Clinical predictors of adverse patient outcomes in an experience of over five thousand chronic endovascular pacemaker and defibrillator lead extractions. Heart Rhythm. 2014 May; 11:799-805.

7. Kay GN, Brinker JA, Kawanishi DT, et al. Risks of spontaneous injury and extraction of an active fixation pacemaker lead: report of the Accufix Multicenter Clinical Study and Worldwide Registry. Circulation 1999; 100: 2344-2352.

8. Kutarski A, Pietura R, Czajkowski M. Difficult dual stage transcutaneous lead extraction complicated by fracture of both leads. Cardiol J 2012; 19:412-17.

9. Love CJ, Wilkoff BL, Byrd CL, et al. Recommendations for extraction of chronically implanted transvenous pacing and defibrillator leads: indications, facilities, training. North American Society of Pacing and Electrophysiology Lead Extraction Conference Faculty. Pacing Clin Electrophysiol. 2000; 23: 544-51.

10. Kutarski A, Malecka B, Zabek A, et al. Broken leads with proximal endings in the cardiovascular system: Serious consequences and extraction difficulties. Cardiol J 2013; 20: 161-9.

11. Michalak M, Kutarski A, Zawadzka-Byśko M, Opolski G, Grabowski M. Transvenous extraction of a broken atrial lead embolised into the pulmonary artery using a pigtail catheter. Kardiol Pol. 2015; 73(6):464. 